
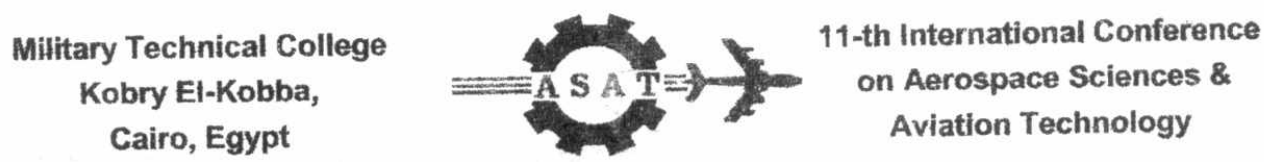

\title{
EVALUATION OF INTERFACE CHARACTERISTICS FOR DIFFERENT JOINTS PRODUCED BY EXPLOSIVE WELDING
}

\author{
M. Abd El.Ghany Fayed", G.M. Abdo", M. Tolba Sallam
}

\begin{abstract}
This study was conducted to evaluate the bonding ability and the interface characteristics for four different joints produced by explosive welding. Three joints were elaborated using copper-nickel alloy as base plate with either stainiess steel, carbon steel and commercially pure aluminum as flyer plates. The fourth joint was of commercially pure aluminum as base plate and carbon steel as flyer plate. Different explosive ratios and stand-off distances were applied. Experimental results showed good bonding quality in all joints. By increasing explosive ratio, at small stand-off distance of $2 \mathrm{~mm}$, flat bonding interface was transformed to a wavy bonding interface in all joints. The form regularity and amplitude of the obtained wavy interface depend on the type of welded materials. Increasing the stand-off distance also transforms the flat interface, obtained at the small explosive ratio $R=1.4$, to a wavy interface, only when the flyer plate was of (FCC) structure. When carbon steel flyer plate of (BCC) structure was used, increasing the stand-off distance showed no major modifications on the interface morphology. It was found that hardness on both sides of the interface was increased due to the high plastic flow that occurs in these regions. This hardening effect was very pronounced in the joints having a flyer plate made of carbon steel with higher coefficient of strain hardening. EDS and WDS analysis showed that diffusion did not take place between the welded plats however, diffusion was observed only in local melting zones along the interface.
\end{abstract}

\section{KEYWORDS}

Explosive ratio, Stand-off distance, Obliquity dynamic angle, Interface morphology, flat and wavy interface.

\footnotetext{
* Lecturer, MTC, Egyptian Armed forces

** Researchers, Res. Center, Egyptian Armed forces.

*** Professor, MTC Egyptian Armed forces.
} 


\section{INTRODUCTION}

Explosive welding is a solid-state process in which controlled detonation of high explosives is used to join two or more materials together under high pressures [1]. In this technique, energy produced by explosives is used to accelerate a material (flyer plate) across a predetermined distance (stand-off distance) into contact with other material (base plate) Fig. 1, and bring the weld surfaces together in a high velocity collision which produces excessive but localized plastic flow at the interacting surfaces [2]. While the process is usually described as a cold technique, meaning that no external heat is used to promote the bonding, high-localized temperatures are normally generated at the welded interface due to the dynamics of the process [3]. The combination of pressure, heat and plastic flow can produce an interface bond having strength equal to or greater than that of the parent material. While the process can be used to weld together two or more pieces of the same metals, its major industrial potential lies in the fact that it can be used to weld together combinations of different metals, many of which are hard or even impossible to join by any other means [4].

Explosive welding and cladding of some metals with a corrosion resistant overlay has a number of advantages and are extensively used in chemical tankers, pressure vessels and pipes to heat exchangers since it is capable of producing large effective area of bonding between the two different welded materials [5]. The explosive welding technique provides a solid-state bond without HAZ to degrade its strength as it is typical of all other heat-dependent welding or joining processes [6].

Morphologically, two types of explosion weld interface can be created, first is the flat or straight-line interface, which occurs only when the collision conditions are at the lower limits for jetting i.e. The obliquity dynamic angle $\beta$ of collision lies above the minimum angles for jetting and below the limiting obliquity angle for wave-no wave boundary. Above this limit the explosion weld interface will have a wavy morphology. This wave formation has been the subject of considerable investigations [7, 8]. Its formation can be explained by the localized dynamic compression of the two metals in the region immediately adjacent to the collision point and weld interface [9]. The compression causes localized bulk flow of the metals which becomes unstable and make the weld interface to deform above and below the theoretical plane of the interface as shown in Fig. 2. The size of the wave pattern is the post-welding characteristic that can be used to determine the collision conditions used to establish the weld. The wavelength or frequency of the interfacial wave in an explosion weld is directly related to the thickness of the prime (Flyer) plate, its angle of collision with the base plate and the amount of energy liberated by the used explosives [10, 11].

The objective of the study is to investigate the nature of the weld interface resulting from explosive welding of different combinations of materials with distinct different properties under various explosive welding conditions. 


\section{EXPERIMENTAL PROCEDURE :}

Parallel plates arrangement was used in the experimental set-up applied for explosive welding of the different combinations of metals and alloys as schematically shown in Fig. 1. four types of distinctly different materials wore used in this study to provide four different joints as shown in Table 1 :

Table 1: Materials combinations adopted for explosive welding

\begin{tabular}{|c|c|}
\hline Base Plate & Flyer Plate \\
\hline Copper-Nickel alloy & Stainless Steel \\
\hline Copper-Nickel alloy & Carbon Steel \\
\hline Commercially pure Aluminum & Carbon steel \\
\hline Copper-Nickel alloy & Commercially pure Aluminum \\
\hline
\end{tabular}

The chemical compositions of these four materials are given in Table 2.

Table 2: Chemical composition (wt \%) of flyer and base plates.

\begin{tabular}{|c|c|c|c|c|c|c|c|c|c|c|c|}
\hline \multirow{2}{*}{ Material } & \multicolumn{11}{|c|}{ Composition (wt \%) } \\
\hline & C & Si & $\mathrm{Mn}$ & $\mathrm{Cr}$ & $\mathrm{Ni}$ & Mo & $P$ & S & $\mathrm{Fe}$ & Al & $\mathrm{Cu}$ \\
\hline Stainless Steal & 0.08 & 0.46 & 1.2 & 18.72 & 9.87 & 2.45 & 0.035 & 0.035 & Batance & - & - \\
\hline Carbon Steel & 0.24 & 0.82 & 1.37 & - & - & - & 0.04 & 0.04 & Batance & - & - \\
\hline $\begin{array}{l}\text { Copper-Nickel } \\
\text { alloy }\end{array}$ & - & - & - & - & 8.5 & - & - & - & - & 21 & Batance \\
\hline $\begin{array}{l}\text { Commercially } \\
\text { pure Aluminum }\end{array}$ & - & 0.35 & 0.23 & - & - & - & - & - & 0.42 & Balance & - \\
\hline
\end{tabular}

Flyer and base plates were designed with dimensions of $250 \times 250 \times 4 \mathrm{~mm}$ and $250 \times$ $250 \times 10 \mathrm{~mm}$ respectively, and were used as received after rolling. Ammonium nitrate base explosives with minimum 3\% TNT were chosen and supplied by the Nobel's Explosive company (NEC), Scotland. The characteristics of these explosives and the established weld parameters are illustrated in table 3.

Table 3: Characteristics of the used explosives and the established

\begin{tabular}{|c|c|c|c|c|c|}
\hline $\begin{array}{c}\text { welonation } \\
\text { velocity } \\
\mathrm{V}_{\mathrm{d}}(\mathrm{m} / \mathrm{s})\end{array}$ & $\begin{array}{c}\text { Density } \\
\left(\mathrm{g} / \mathrm{cm}^{3}\right)\end{array}$ & $\begin{array}{c}\text { Explosive } \\
\text { Ratio, } \mathrm{R}\end{array}$ & $\begin{array}{c}\text { Velocity of } \\
\text { flyer plate } \mathrm{V}_{\mathrm{p}} \\
(\mathrm{m} / \mathrm{s})\end{array}$ & $\begin{array}{c}\text { Obliquity } \\
\text { dynamic } \\
\text { angle } \beta \\
(\mathrm{deg})\end{array}$ & $\begin{array}{c}\text { Stand-off } \\
\text { distance } \\
\mathrm{S}(\mathrm{mm})\end{array}$ \\
\hline $3400-3600$ & 0.85 & 1.4 & 882 & 14.4 & 2,8 \\
\hline
\end{tabular}


The explosive welded joints were carried out using mainly two values of Explosive ratio $R=1.4,2.8$ and two values of stand off distance $S=2 \mathrm{~mm}$, $8 \mathrm{~mm}$.

Metallographic examination of the different specimens and the nature of the corresponding interface were carried out using optical and scanning electron microscope (SEMA 202). Energy-Dispersive X-ray Spectrometry (EDS) and waveDispersive X-ray spectroscopy (WDS) were used to determine the variation of composition and the distribution of the different elements along a line through the interface

Micro-hardness measurements were carried out using a micro-hardness testing machine type Zwick $32 / 20$ using a load of $100 \mathrm{~g}$. For each specimen, three measurements were taken at the different distances from the interface and the average values were determined to establish the hardness distribution along the interface.

\section{RESULTS AND DISCUSSIONS}

According to the used values of explosive ratio $R$ and the detonation velocity of explosive $V_{d}$ the speed of the flyer plate $V_{p}$ and obliquity dynamic angle $\beta$ were determined as shown in Table 3 . Increasing the explosive ratio from $(R=1.4)$ to double its value $(R=2.8)$ increases the flyer plate velocity $V_{p}$ from $882 \mathrm{~m} / \mathrm{s}$ to 1250 $\mathrm{m} / \mathrm{s}$ and the obliquity dynamic angle $\beta$ from $14.4^{\circ}$ to $20.5^{\circ}$. stand-off distance (S) was adjusted to be either $2 \mathrm{~mm}$ or $8 \mathrm{~mm}$.

Fig. 3, illustrates the explosive welded joint of stainless steel and Copper-Nickel alloy using a stand-off distance $S=2 \mathrm{~mm}$ and an explosive ratio $\mathrm{R}=2.8$. We can note that the obtained interface has regular wavy structure generated due to the formation of transient fluid like behavior under high pressure in the collision region $[12,13]$. This type of interface is characterized by better mechanical properties [14]. The distributions of $\mathrm{Fe}$ and $\mathrm{Cu}$ along a line through the joint interface by $x$-ray wave dispersive spectrometry (WDS) are shown in Figs. 4 and 5, where we can note that the transition of the distribution at the interface is very sharp and abrupt indicating that no diffusion took place. Moreover, this fact was also confirmed by analyzing the joint at $10 \mu \mathrm{m}$ from both sides of the interface using $x$-ray energy dispersive spectrometry (EDS). It can be seen from Figs. 6 and 7. that the results of the EDS analysis in the stainless steel and copper sides showed similar contents to that illustrated in Table 2 and indicating that there was no-diffusion through the interface during the explosive welding process. This results is consistent with the published previous works $[15,16]$. The wavy interface was transformed into a flat interface when the explosive ratio is decreased to 1.4 as shown in Fig. 8.

When a wider stand-off distance $(S=8 \mathrm{~mm})$ was used a wavy interface was obtained even in the case of low explosive ratio $(R=1.4)$ as illustrated in Fig. 9, where the distribution of $\mathrm{Fe}$ and $\mathrm{Cu}$ were given along the initial interface.

Fig. 10, illustrates the explosive welded joint of carbon steel and copper-nickel alloy obtained using a stand-off distance $S=2 \mathrm{~mm}$ and an explosive ratio $R=2.8$. The resulting interface is of irregular wavy nature of relatively small amplitude that can be 
attributed to the internal structure of the used carbon steel which is Ferritic-pearlitic and possesses higher coefficient of strain hardening.

On the other hand, the interface is outlined by the characteristic sharp transition between the two materials, nevertheless, local melting zones were also encountered in some regions along the interface. In fact, the dissipation of the kinetic energy at the interface as a source of heat may be sufficient specially under high explosive ratio to cause bilateral melting across the interface and diffusion within the molten layers. As illustrated in Fig. 11. EDS analysis on carbon steel side, copper-nickel alloy side, and local melting zone are illustrated in Fig. 12. We can note that the EDS analysis in the local melting zone contain important contents of $\mathrm{Fe}$ and $\mathrm{Mn}$ which were not originally present in the copper-nickel alloy, confirming the occurrence of diffusion within the local melting layer. When the explosive ratio was reduced to 1.4 for the same joint and stand-off distance the interface reveals only a flat morphology as shown in Fig. 13. When the stand-off distance was increased to $S=8 \mathrm{~mm}$ the interface morphology was not subjected to major modifications.

The explosive welded joint of carbon steel and commercially pure aluminum obtained using a stand-off distance $\mathrm{S}=2 \mathrm{~mm}$ and an explosive ratio $\mathrm{R}=2.8$ is illustrated in Fig. 14. The resulting interface revealed a coarse wavy stretched morphology, where a high degree of rotation takes place with clear sign of local melting as shown in Fig. 15. This form of interface was explained by the formation of front vortex due to flow instability, indentation action, and trapping of re-entrant jet $[17,18]$.

This form of interface allows the formation of high degree of interlocking between both welded materials and consequently provide extremely high contact area along the formed interface as shown in Figs. 16 and 17. The morphology of such interface is usually characterized by high mechanical properties. When the explosive ratio was decreased to $R=1.4$ the welded joint provided a flat interface as shown in Figs. 18 and 19 .

This flat interface remains flat even if the sand-off distance was increased to $S=8$ $\mathrm{mm}$, which confirms that the structure of the flyer plate plays a major role in controlling the nature and morphology of the resulting interface.

Fig. 20, illustrates the explosive weided joint of commercially pure aluminum and copper-nickel alloy using a stand-off distance $S=2 \mathrm{~mm}$ and an explosive ratio $R=2.8$. The resulting interface is of small amplitude wavy nature. In some regions along the interface a clear local melting zone can be seen as shown in Figs. 21 and 22. which can be attributed to the high pressure generated by using a high explosive ratio.

On the other hand, the distribution of both Aluminum and copper along a line perpendicular to the interface by WDS showed a gradual variation of one side of the joint to the other which proves the occurrence of sensible diffusion in this melting zone. When the explosive ratio was reduced to 1.4 for the same stand-off distance and the same type of joint, the interface becomes completely flat without any signs of local melting as shown in fig. 23 . Increasing the stand-off distance to $\mathrm{S}=8 \mathrm{~mm}$ a wavy interface was obtained for any value of the explosive ratio $R$.

Hardness was measured along a line perpendicular to the interface in each type of the adopted joints and under different values of explosive ratio ( $R$ ) and stand-off distance $(S)$ to determine the resulting hardening that may take place in each joint on both sides of the interface due to the induced plastic flow. Different degrees of 
hardening was obtained in each joint but the maximum hardening effect was produced when the stand-off distance was $S=8 \mathrm{~mm}$ and the explosive ratio was $R=2.8$. Figs. $24,25,26$ and 27 , display the hardness distributions measured on the different joints when the stand-off distance was $S=8 \mathrm{~mm}$. It can be noted generally that the maximum hardening effect was realized when the high explosive ratio $R=$ 2.8 was applied. Moreover, the used carbon steel with its ferritic-pearlitic nature demonstrates the highest degree of strain hardening. This can justify and explain the nature of the morphology of the obtained interface obtained in this case which revealed net difference from those material having austenitic or FCC structures.

\section{CONCLUSIONS:}

1. Couples of dissimilar materials having different melting points cannot be joined by conventional welding methods; however these couples can be joined by explosive welding using suitable parameters.

2. For small stand-off distance $(S=2 \mathrm{~mm})$ the obtained interface in all joints was flat, in case of using low explosive ratio $(R=1.4)$. This interface transforms into wavy form when using higher explosive ratio $(R=2.8)$.

3. The form, regularity and amplitude of the obtained wavy interface depend on the composition and structure of welded materials.

4. When a big stand-off distance $(S=8 \mathrm{~mm})$ was used wavy interface was obtained, even in the case of low explosive ratio $(R=1.4)$, in the joints made of plates having FCC structure (stainless steel/ Cu-Ni alloy and pure aluminum / Cu-Ni alloy).

5. On the contrary, when a big stand-off distance $(\mathrm{S}=8 \mathrm{~mm})$ was used in the explosive welding of joints having a flyer plate made of carbon steel of BCC structure the interface morphology was not subjected to major modifications compared to the case when small stand-off distance $(\mathrm{S}=2 \mathrm{~mm})$ was used. This proves that the flyer plate structure has a deep effect on the interface morphology of explosive welded joint.

6. EDS and WDS analysis proved that the explosive welding is a diffusion less joining process, nevertheless when the explosive ratio is high $(R=2.8)$, local melting zones can be observed along the interface, where diffusion may take place.

7. Hardness measurements revealed the occurrence of sensible hardening on both sides of the interface in all joints due to the significant cold plastic deformation. This hardening effect is very pronounced in the joints having a flyer plate made of carbon steel of BCC structure and characterized by a high coefficient strain hardening. 


\section{REFERENCES :}

[1] Brasher D.G., Butler D.J.," Explosive welding : principles and potentials" , J. Adv. Mater. Proc. 1995; 3; 37-38.

[2] Patterson R.A., "Fundamentals of explosive welding", ASM Handbook, 1993; 6; 160-164.

[3] Nishida M.H., Chibia A., Honda Y., Hirazumi J., Horikiri K., "Electron microscopy studies of bonding interface in explosively welded Ti / steel clads", ISIJ Int., 1995; 35;217.

[4] Kim S.J., Paik S.H., Huh M.Y., "Applications of explosive welding", J. Korean Inst. Met. Mater., 1994; 32; 1558.

[5] Fan Y., Tysoe B., Sim J., Mirkhani K., Sinclair A.N., Honarvar F., "Ultrasonic Weld Inspection of explosive welded joints" J. Mater. Sci., 2003; 41 (5) ; 369-375.

[6] Varol I., Lippold J.C., Baeslack W.A., "Mechanical properties of thermo-bimetals produced by explosive welding" , J. Eng. Mater., $1992 ; 6977 ; 217-252$.

[7] Yano S., Matsui H., Morozumi S., "Structural observations of the interface of explosive-bonded Mo / Cu system" , J. Mater. Sci., 1998; $33 ; 4857$.

[8] Ege E., Inal O.T., Zimmerly C.A., "Response surface study on production of explosively-welded Al / Ti laminates", J. Mater. Sci. $1998 ; 33 ; 5327$.

[9] Abe A., "Explosion bonding process", J. Mater. Proc. Technol., 1999 ; $85 ; 162-165$.

[10] Hokomato K., Izuma T., Fuijita M., "New explosive weiding technique to weld aluminum and stainless steel plates", Metallurg. Trans., 1993; A $24 \mathrm{~A} ; \quad 2289-2297$.

[11] Charles J., "Assessment of the quality of the explosive joining of duplex stainless steel" , Proceedings of the Fourth International Conference Duplex Stainless Steel 94, Glasgow, Scotland, 1994; vol. 1 ; 13-16.

[12] Acarer M., Gulenc B., Findik F., “Investigation of explosive welding parameters", J. Mater. Des. 2003; 24 (8); 659-664. 
[13] Kacar R., Acarer M., "Microstructure-property relationship in explosively welded duplex stainless steel-steel" , J. Mater. Sci. Eng., $2003 ; 363(1-2) ; \quad 290-296$.

[14] Han J.H., Ahn J.P., Shin M.C., "Effect of interlayer thickness on shear deformation behaviour of AA5083 Al-alloy / SS41 steel plates manufactured by explosive welding", J. mater. Sci. 2003; 38; 13-18.

[15] Lancaster F.J., "Metallurgy of weiding" , Cambridge Abington Publishing; 1999; vol. 6; 25-50

[16] Raghugandan K., Rathinasabapathi M., Vaidyanathan P.V., Balasubramanian V., "Procedure development and process considerations for explosion welding" J. Mater. Proc. Technol., 1997; $63 ; 55-59$.

[17] Richman R.H., Rao A.S., Kung D., "Explosive cladding of mild steel and aluminium", J. Mater. Proc. 1995; 80/85; 181-183.

[18] Zimmerly C.A., inal O.T., Richman R.H., "Explosive welding of nickeltitanium alloy to low carbon steel" , J. Mater. Sci. Eng. 1994; 188A; 251-254. 

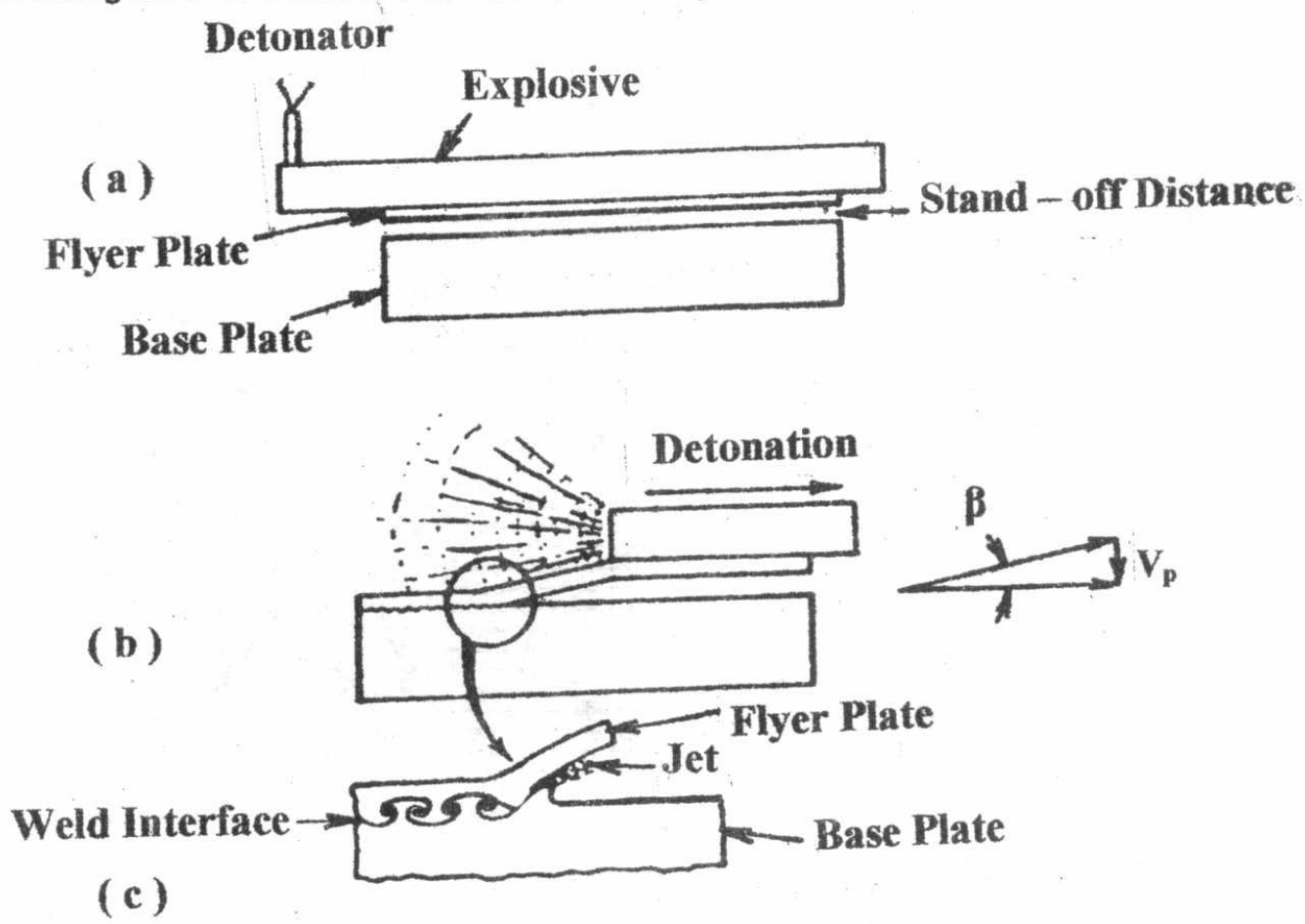

Fig. 1. (a) Explosive welding set-up, (b) detonation wave propagation during welding, (c) Jet formation and establishing of welding interface.

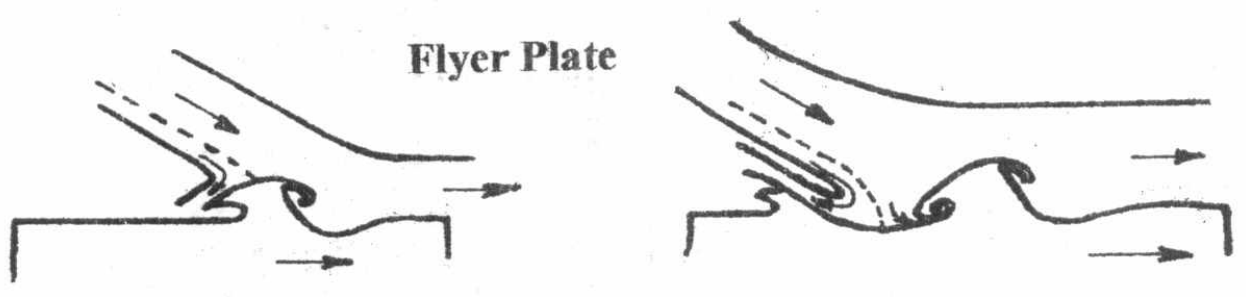

Base Plate

Weld Interface

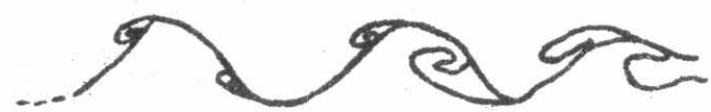

Fig. 2. The localized bulk flow and indentation action of the metals at the weld interface to form the wavy pattern. 


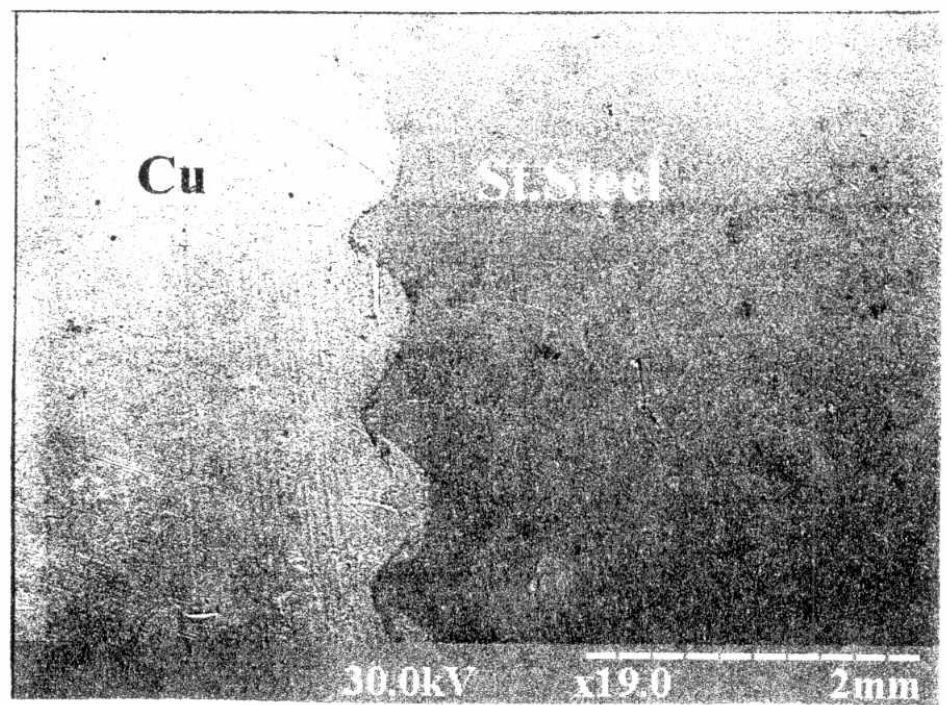

Fig. 3. Explosive welded joint of Stainless Steel and Copper-Nickel alloy obtained using a stand-off distance $S=2 \mathrm{~mm}$ and an explosive ratio
$R=2.8$.

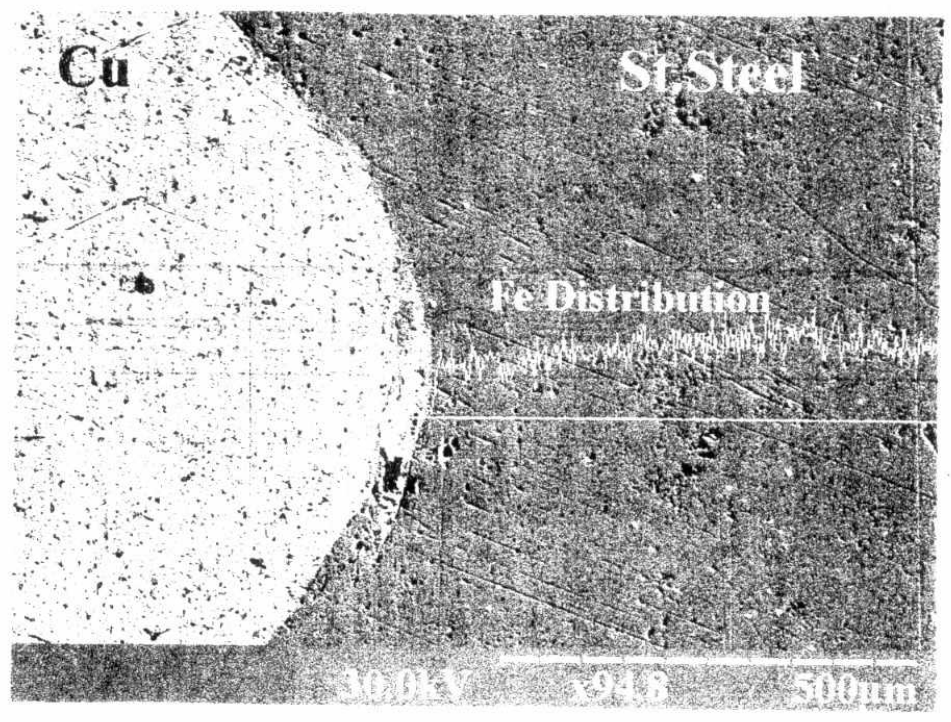

Fig. 4. WDS line analysis of Fe through the interface of Explosive welded joint of St. Steel and $\mathrm{Cu}-\mathrm{Ni}$ alloy $\mathrm{S}=2 \mathrm{~mm}$ and $\mathrm{R}=2.8$. 


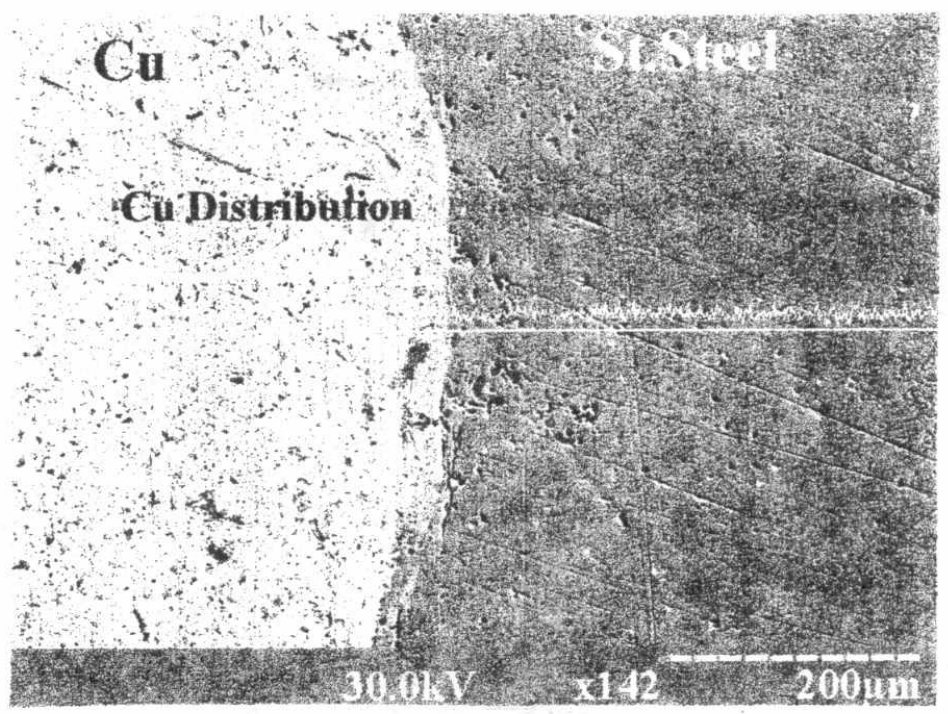

Fig. 5. WDS line analysis of $\mathrm{Cu}$ through the interface of Explosive welded joint of St. Steel and Cu-Ni alloy $\mathrm{S}=2 \mathrm{~mm}$ and $\mathrm{R}=\mathbf{2 . 8}$.

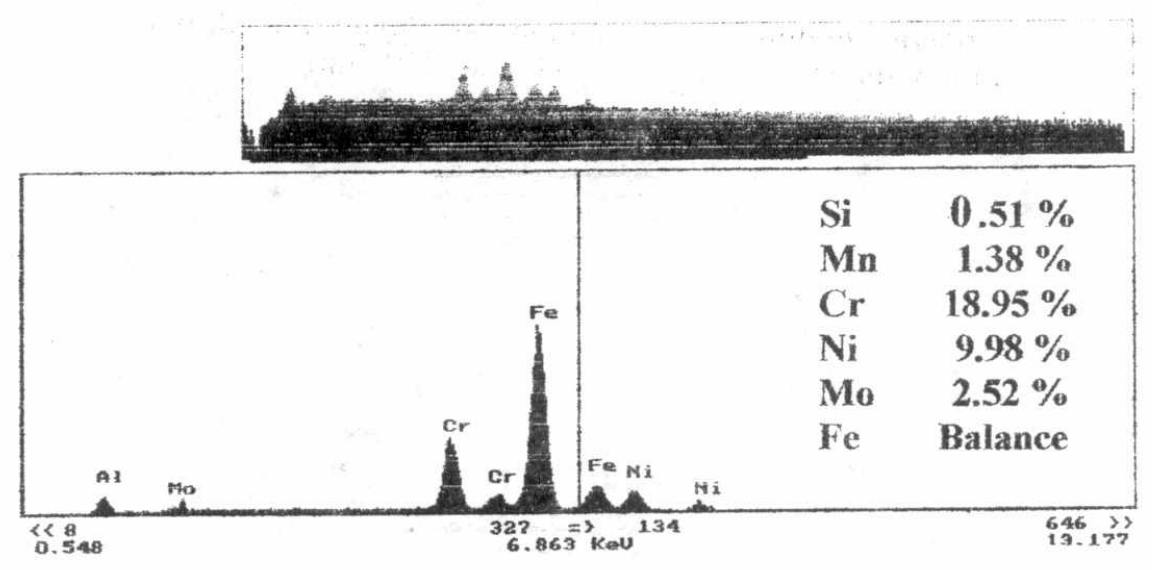

Fig. 6. EDS analysis at $10 \mu \mathrm{m}$ from the interface in the Stainless Steel side for the joint of $\mathrm{Cu}-\mathrm{Ni}$ alloy $/ \mathrm{St}$. Steel. $\mathrm{S}=2 \mathrm{~mm}$ and $\mathrm{R}=2.8$. 


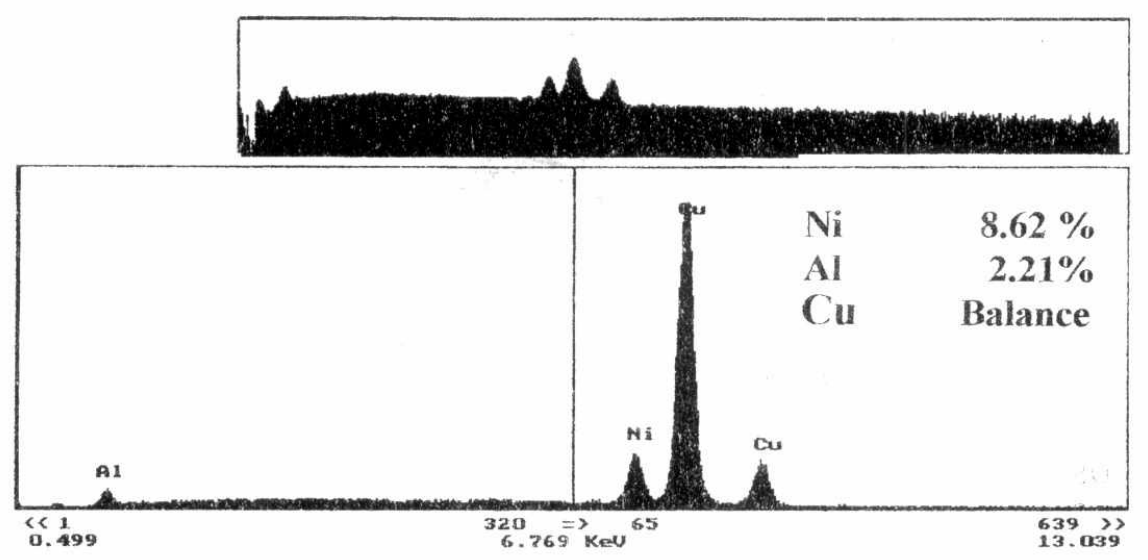

Fig. 7. EDS analysis at $10 \mu \mathrm{m}$ from the interface in the Cu-Ni alloy side for the joint of $\mathrm{Cu}-\mathrm{Ni}$ alloy / Stainless Steel. $\mathrm{S}=2 \mathrm{~mm} \quad \mathrm{R}=2.8$.

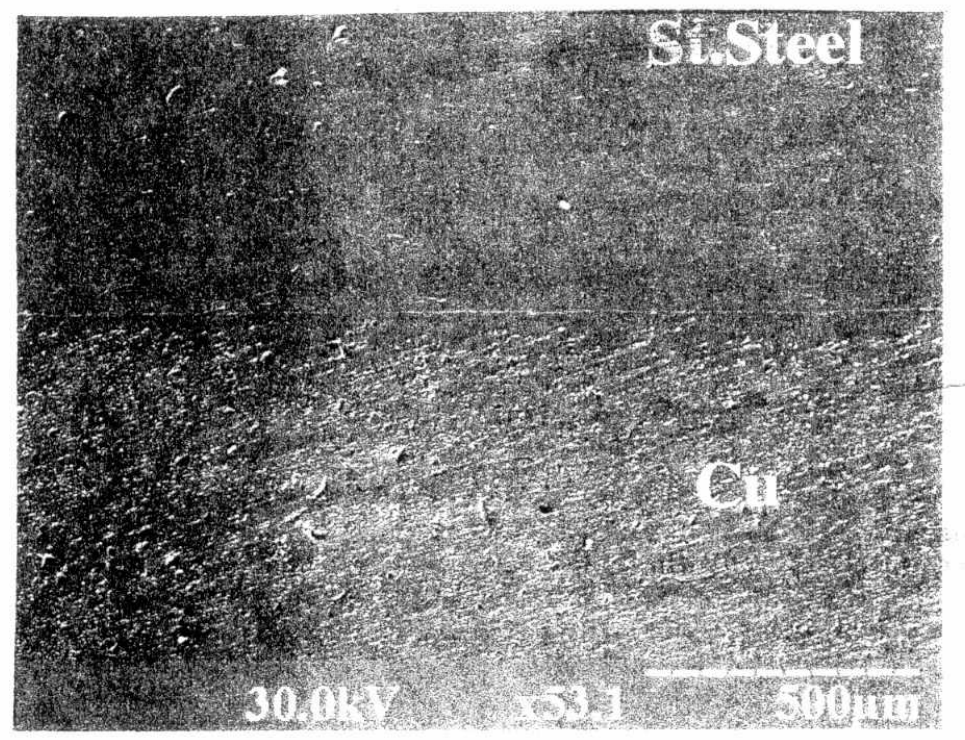

Fig. 8. Explosive welded joint of Stainless Steel and Copper-Nickel alloy obtained using a stand-off distance $S=2 \mathrm{~mm}$ and an explosive ratio $R=1.4$. 

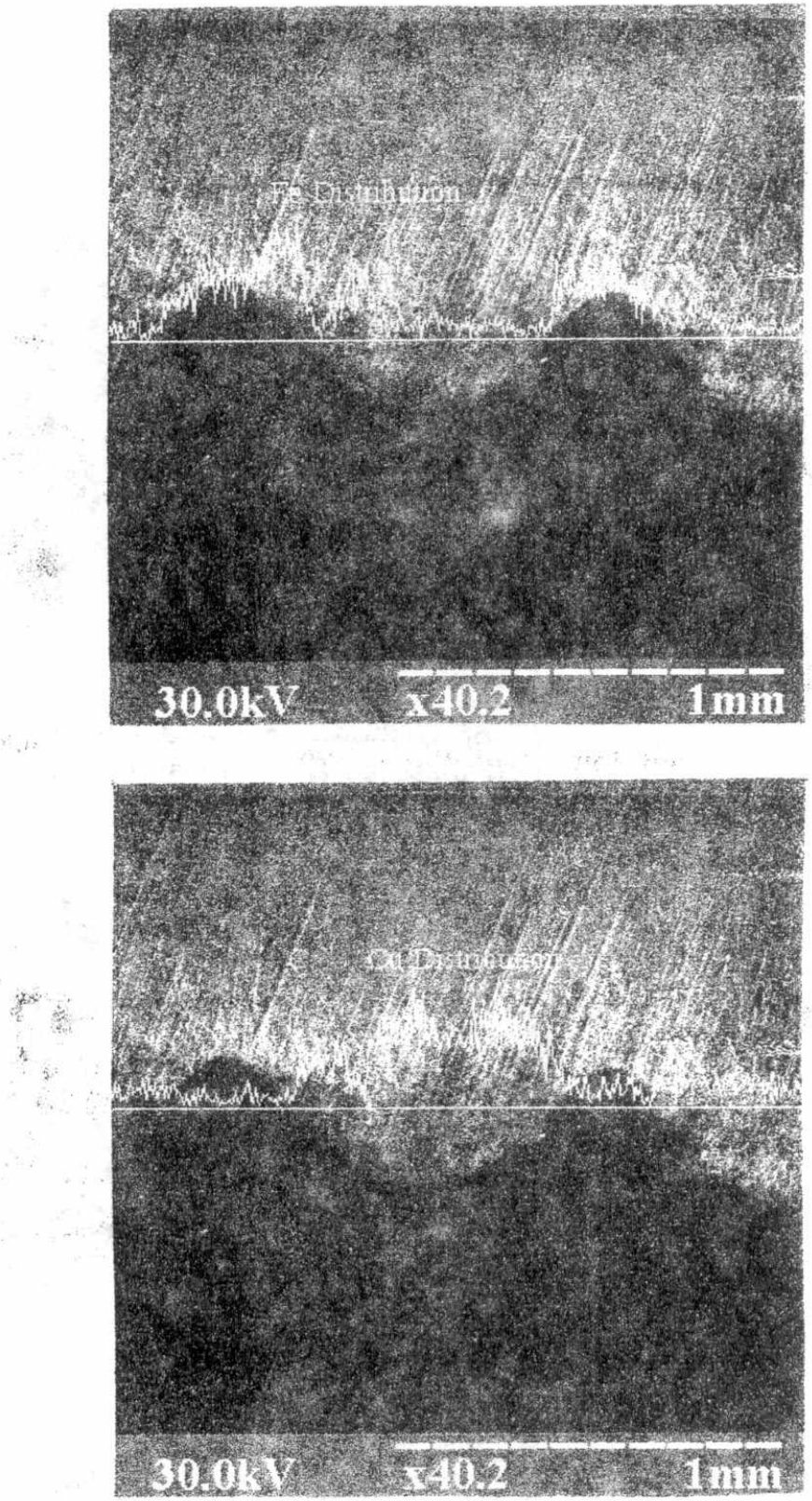

Fig. 9. Explosive welded joint of Stainless Steel and Copper-Nickel alloy obtained using a stand-off distance $S=8 \mathrm{~mm}$ and an explosive ratio $R=1.4$. 


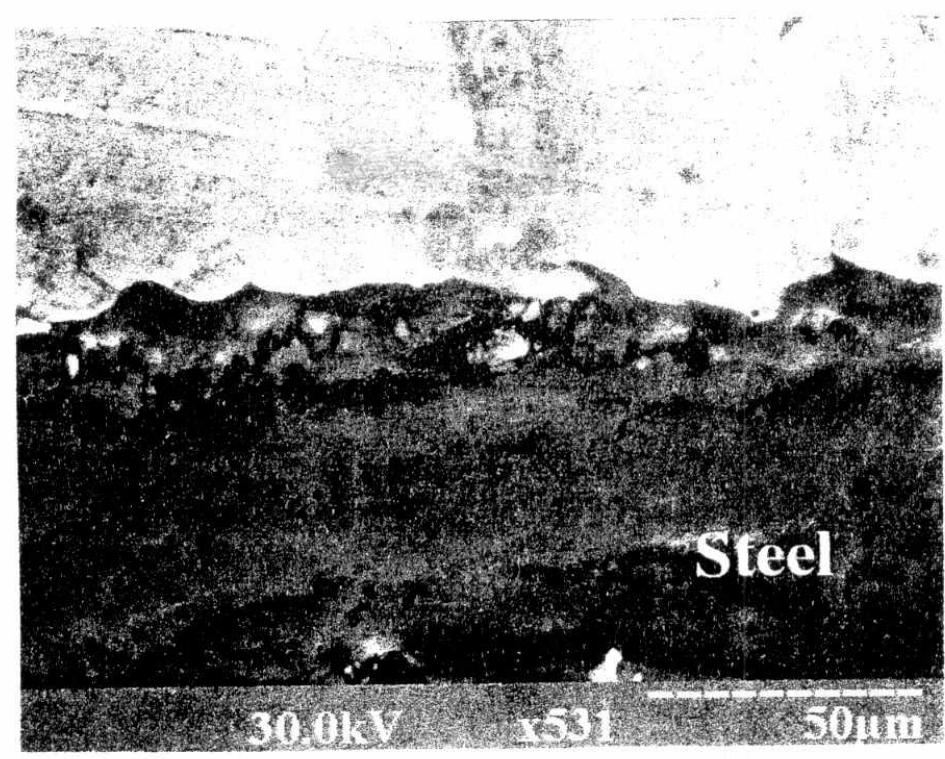

Fig. 10. Explosive welded joint of Carbon Steel and Copper-Nickel alloy obtained using a stand-off distance $\mathrm{S}=2 \mathrm{~mm}$ and an explosive ratio $\mathbf{R}=2.8$.

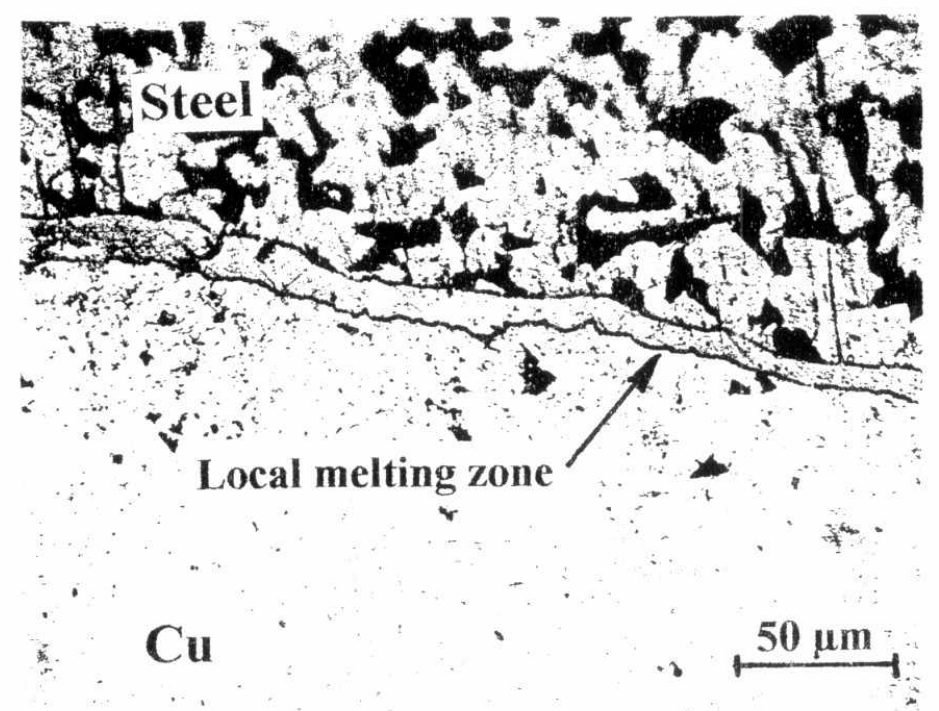

Fig. 11. Optical micrograph of local melting zone along the interface in the explosive welded joint of $\mathrm{C}$. Steel and $\mathrm{Cu}-\mathrm{Ni}$ alloy obtained using a stand-off distance $S=2 \mathrm{~mm}$ and an explosive ratio $\mathrm{R}=2.8$. 


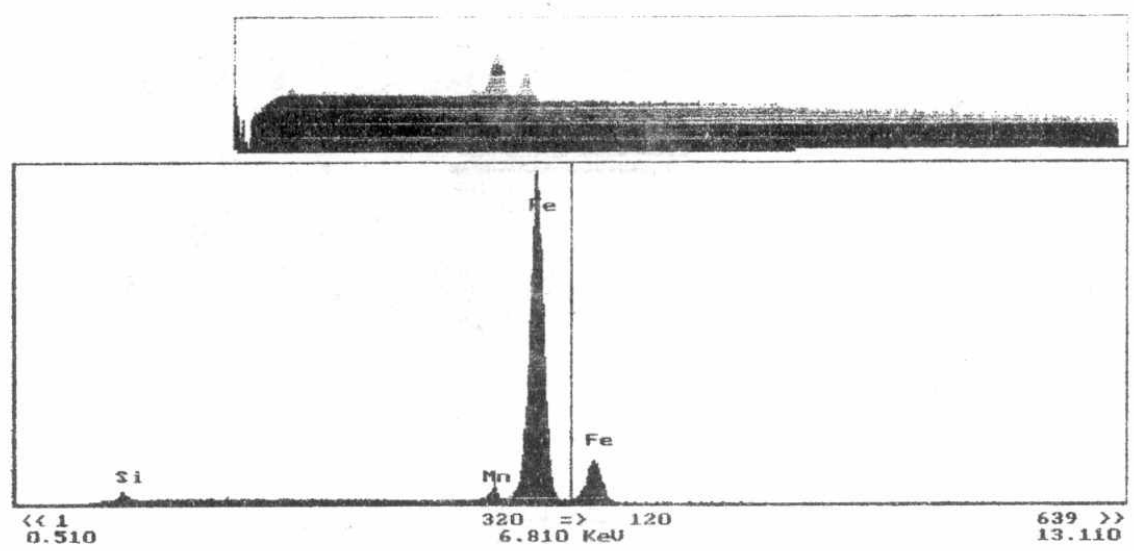

(a)
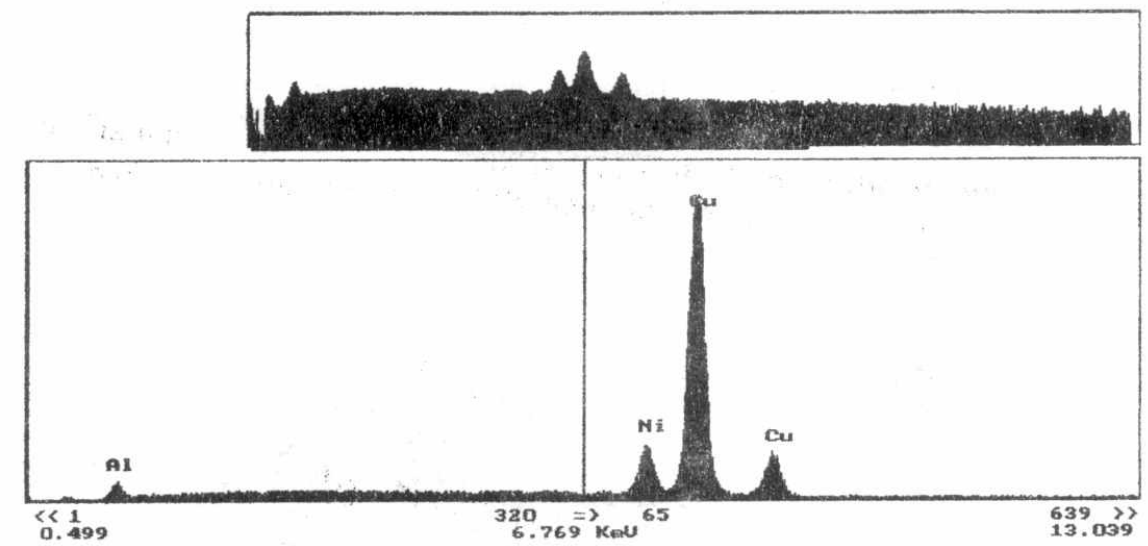

(b)
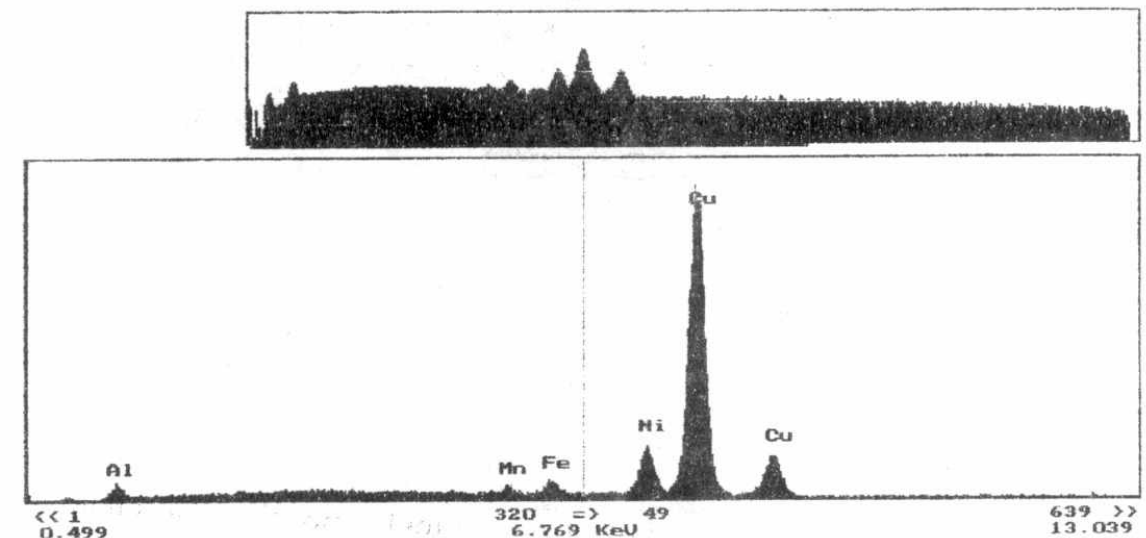

(c)

Fig. 12. EDS analysis obtained at:
(a) Carbon Steel side
(c) Local melting zone
(b) Copper-Nickel alloy side 


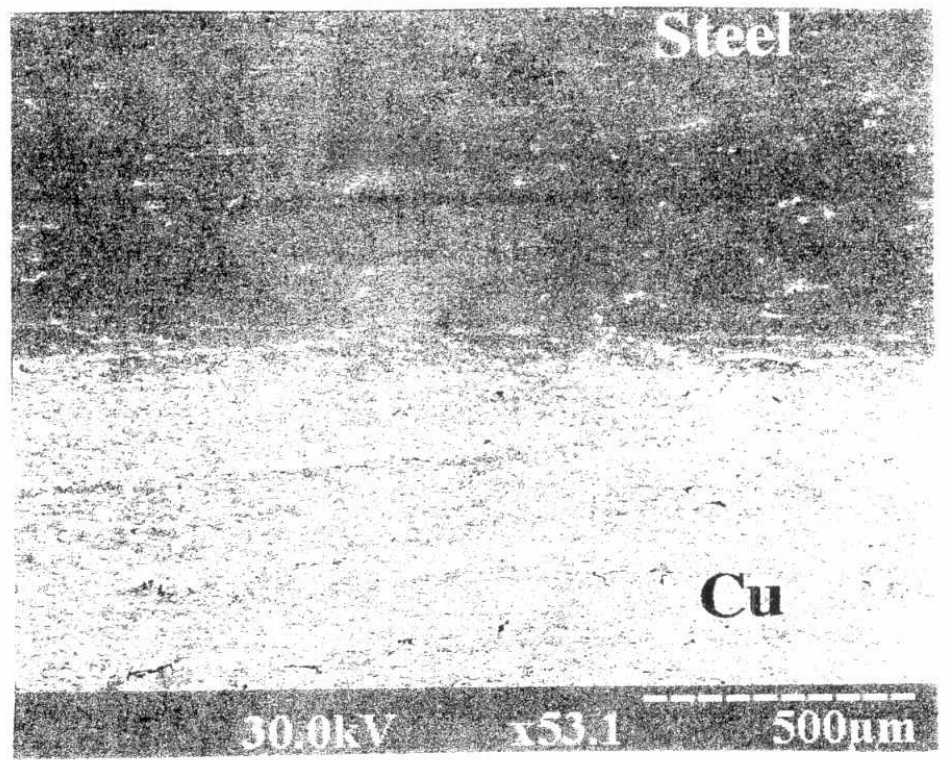

Fig. 13. Explosive welded joint of Carbon Steel and Copper-Nickel alloy obtained using a stand-off distance $S=2 \mathrm{~mm}$ and an explosive ratio $R=1.4$.

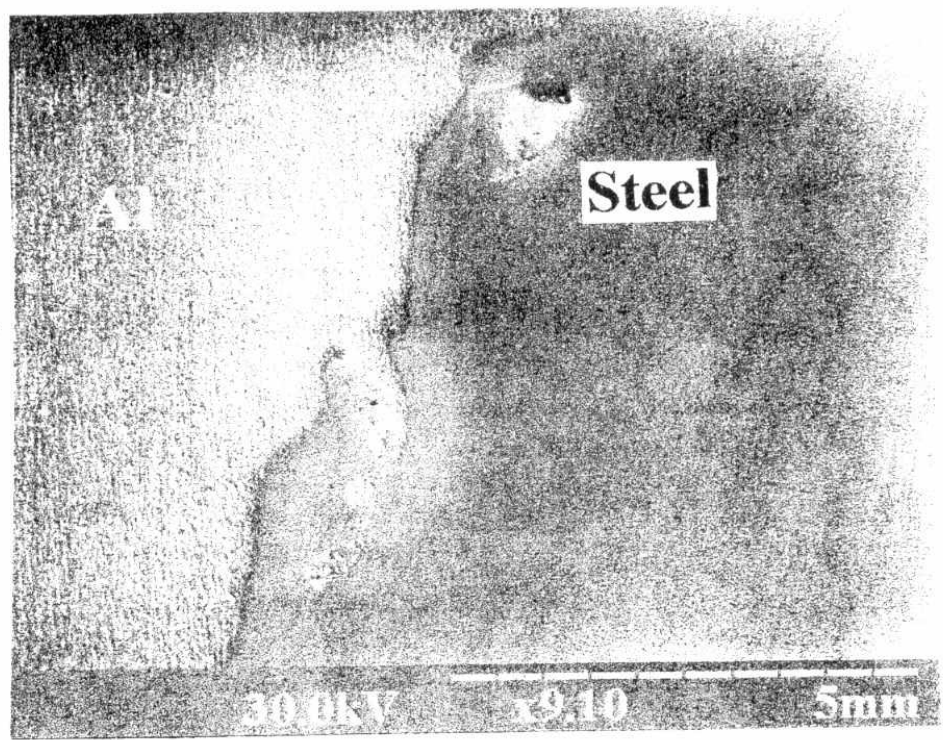

Fig. 14. Explosive welded joint of Carbon Steel and Commerciaily pure Aluminum obtained using a stand-off distance $S=2 \mathrm{~mm}$ and an explosive ratio $\mathrm{R}=2.8$. 


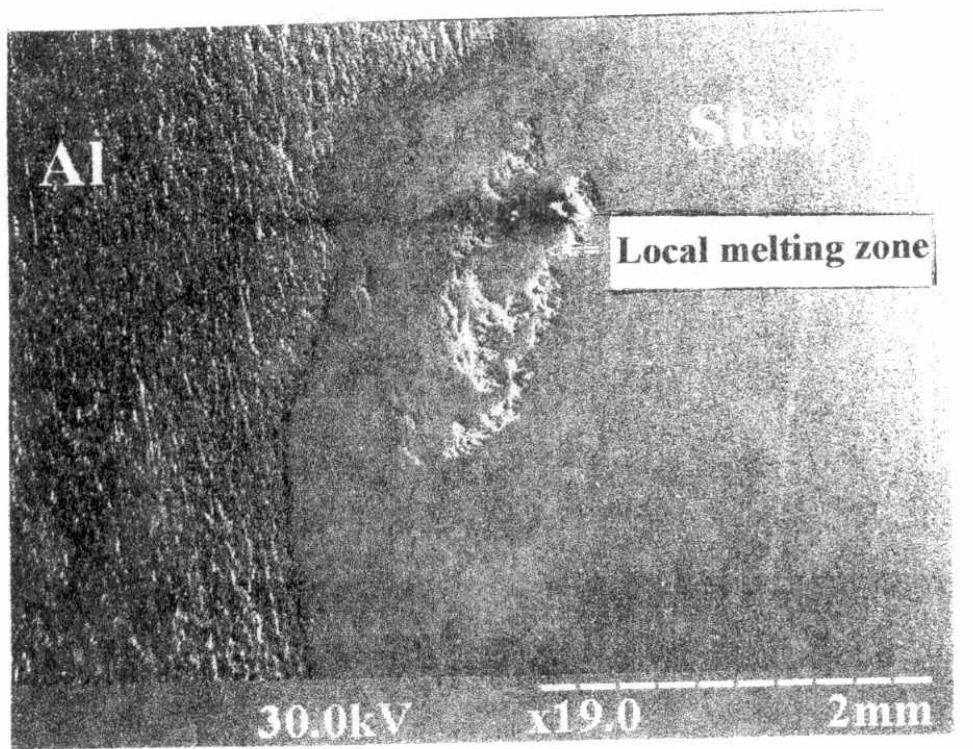

Fig. 15. Course wavy morphology of the interface with clear sign of local melting of the explosive welded joint of Carbon Steel and Commercially pure Aluminum. $S=2 \mathrm{~mm}$ and $\mathrm{R}=2.8$.

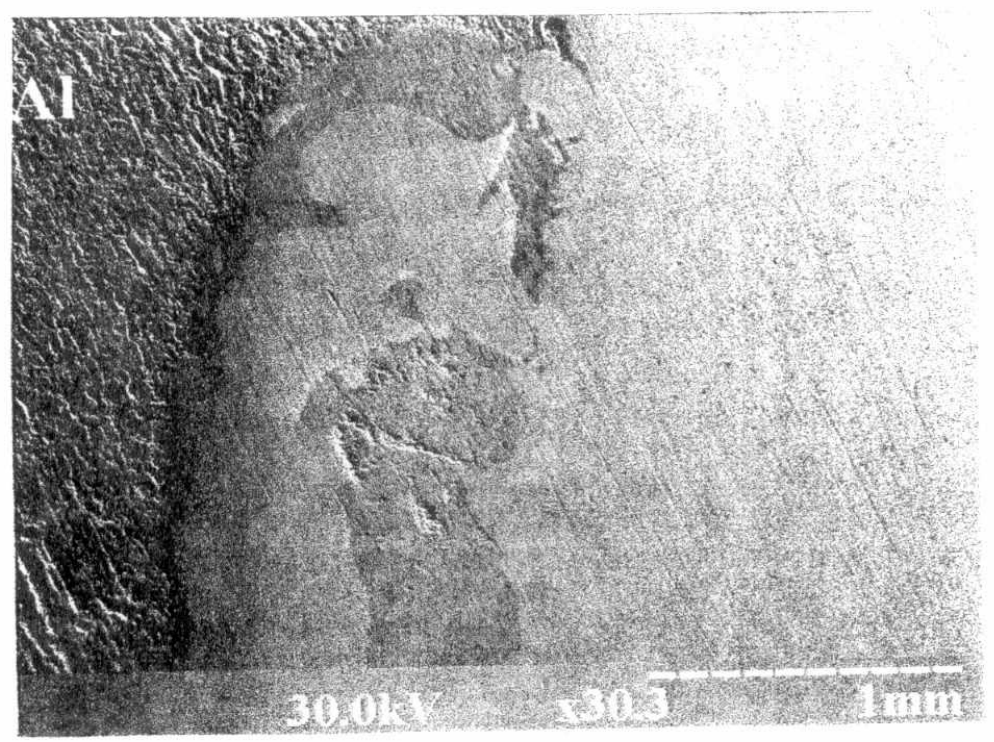

Fig. 16. Formation of high degree of interlocking between welded materials in the explosive welded joint of Carbon Steel and Commercially pure Aluminum. $\mathrm{S}=2 \mathrm{~mm}$ and $\mathrm{R}=2.8$. 


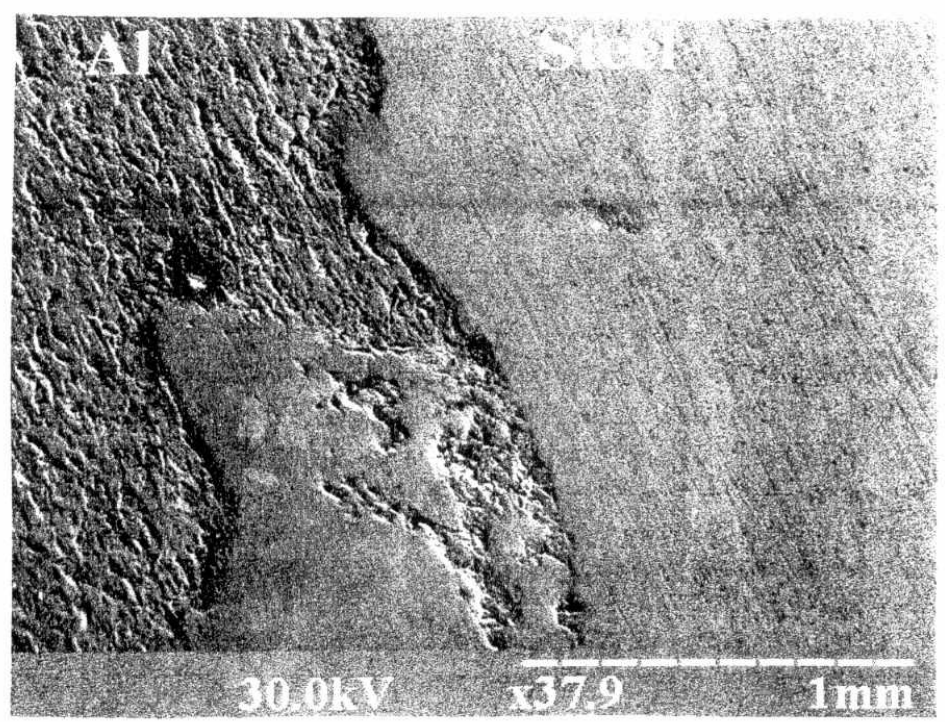

Fig. 17. Formation of extremely high contact area along the formed interface in the explosive welded joint of Carbon Steel and commercially pure Aluminum. $S=2 \mathrm{~mm}$ and $R=2.8$.

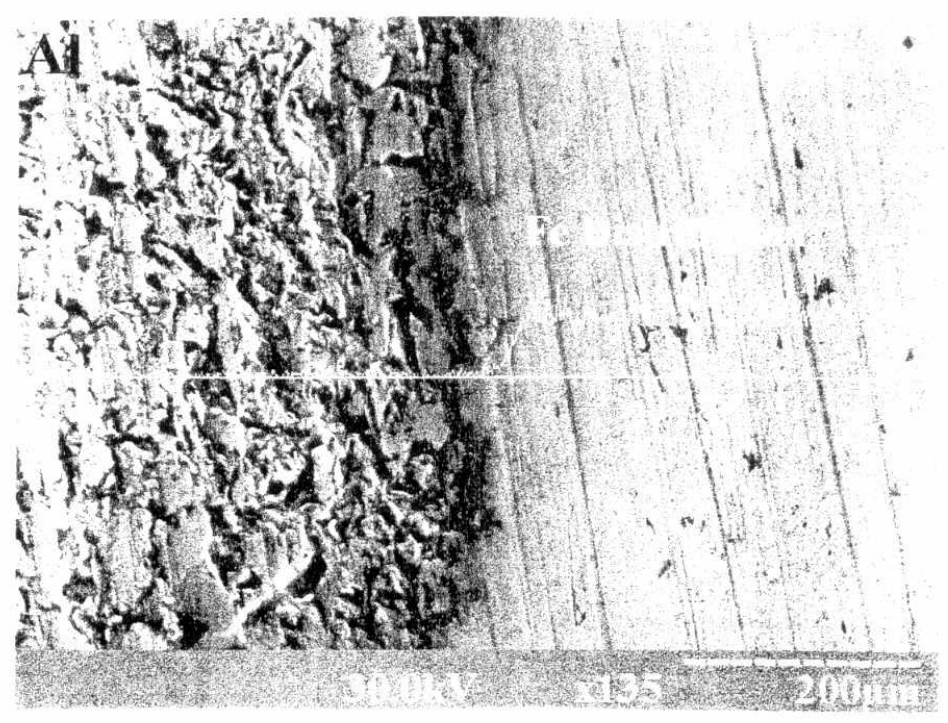

Fig. 18. Explosive welded joint of Carbon Steel and Commercially pure Aluminum obtained using a stand-off distance $\mathrm{S}=2 \mathrm{~mm}$ and an explosive ratio $R=1.4$. (WDS line distribution of $\mathrm{Fe}$ ). 


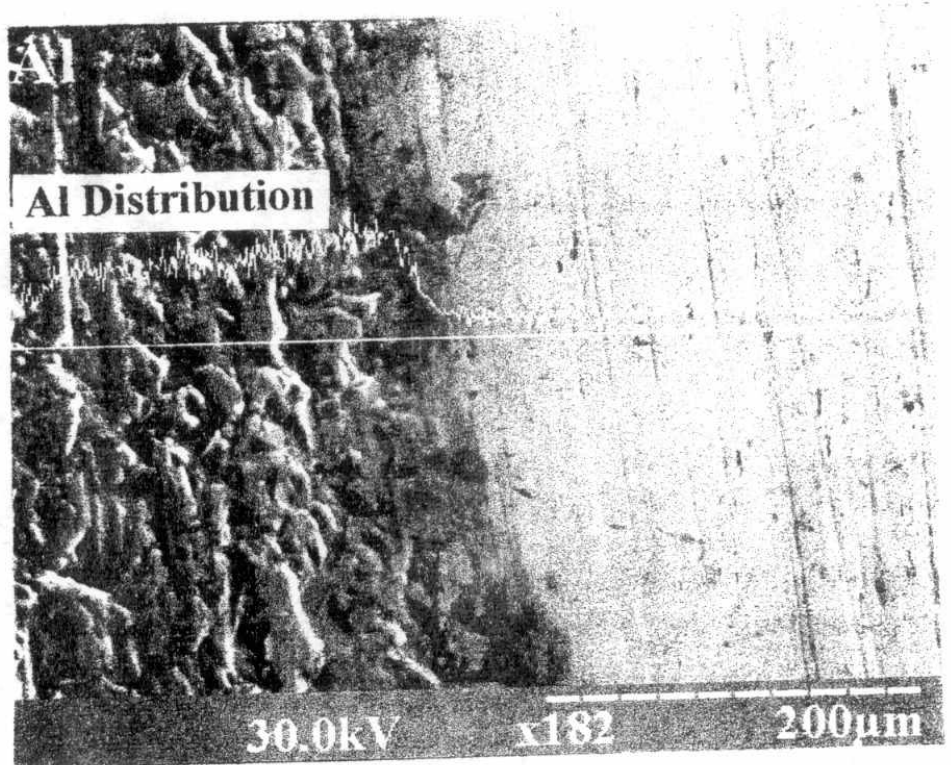

Fig. 19. Explosive welded joint of Carbon Steel and Commercially pure Aluminum obtained using a stand-off distance $S=2 \mathrm{~mm}$ and an explosive ratio $R=1.4$. (WDS line distribution of $\mathrm{Al}$ ).

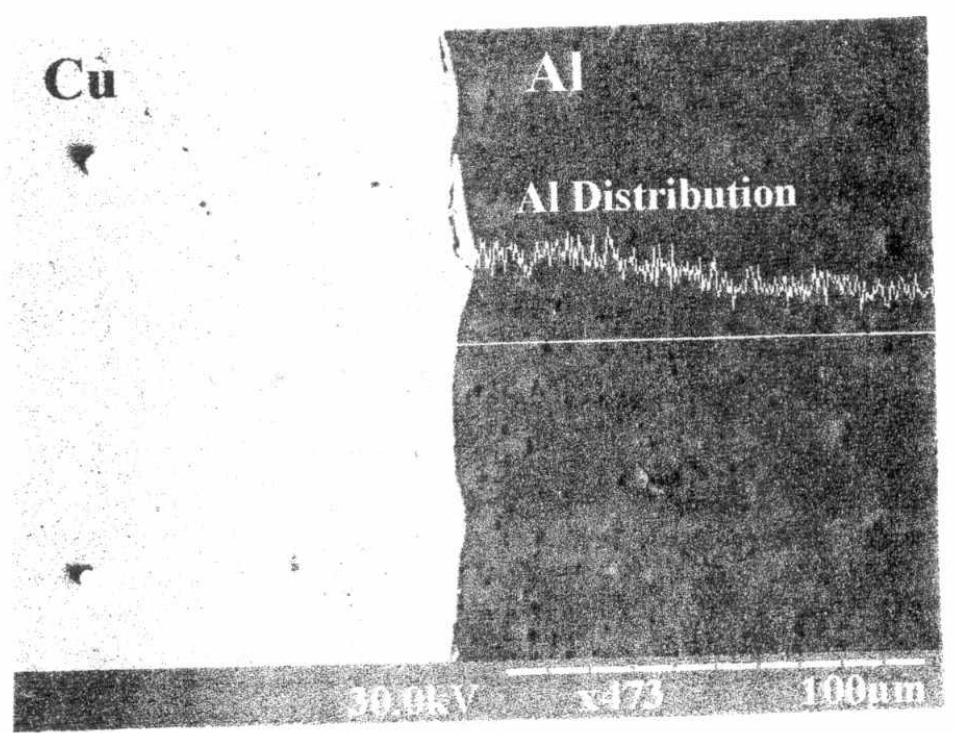

Fig. 20.Explosive welded joint of Commercially pure Aluminum and CopperNickel alloy using a stand-off distance $S=2 \mathrm{~mm}$ and an explosive ratio $\mathbf{R}=\mathbf{2 . 8}$. 


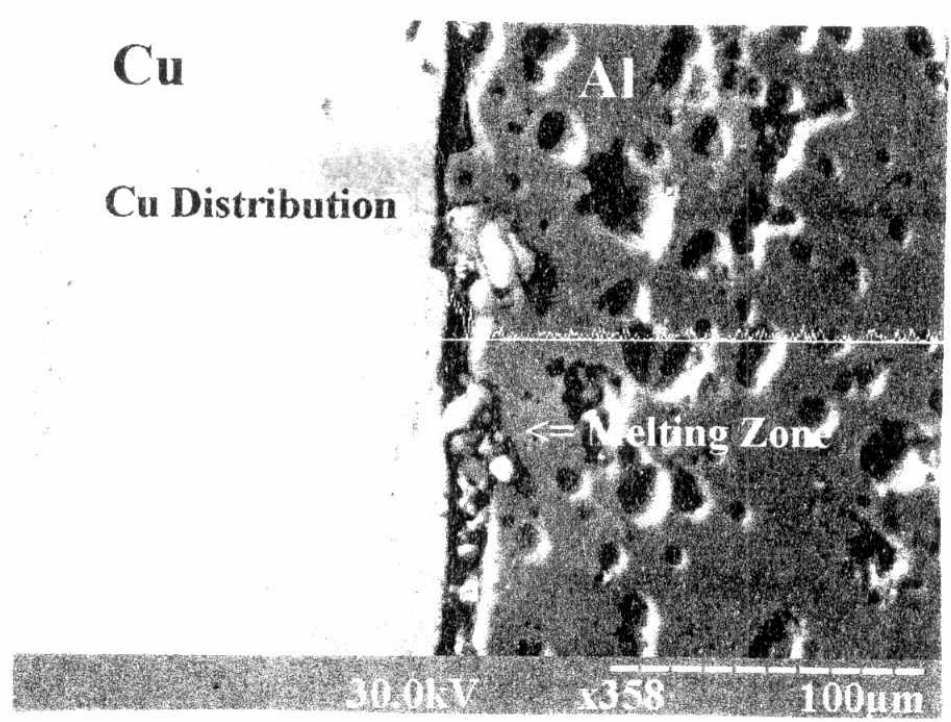

Fig. 21.Local melting zone along the interface in the explosive welded joint of Commercially pure Aluminum and Copper-Nickel alloy $S=2 \mathrm{~mm}$ and $\mathrm{R}=$ 2.8. (WDS line distribution of $\mathrm{Cu}$ ).

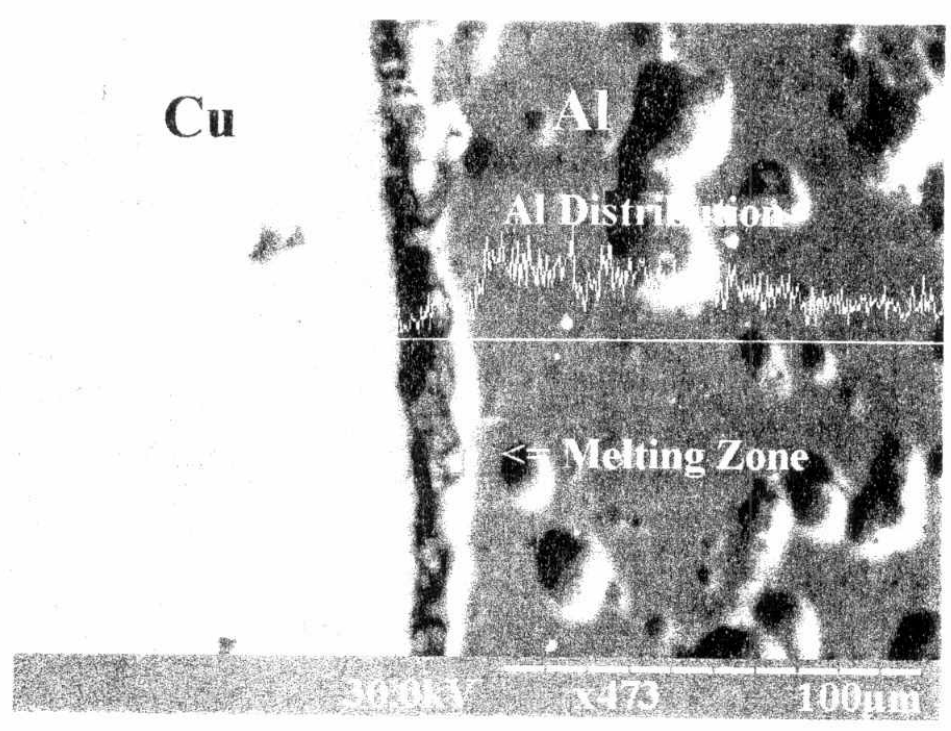

Fig. 22.Local meiting zone along the interface in the explosive welded joint of Commercially pure Aluminum and Copper-Nickel alloy $S=2 \mathrm{~mm}$ and $\mathrm{R}=$ 2.8. (WDS line distribution of Al). 


\section{$\mathrm{Cu}$}

Cu Distribution
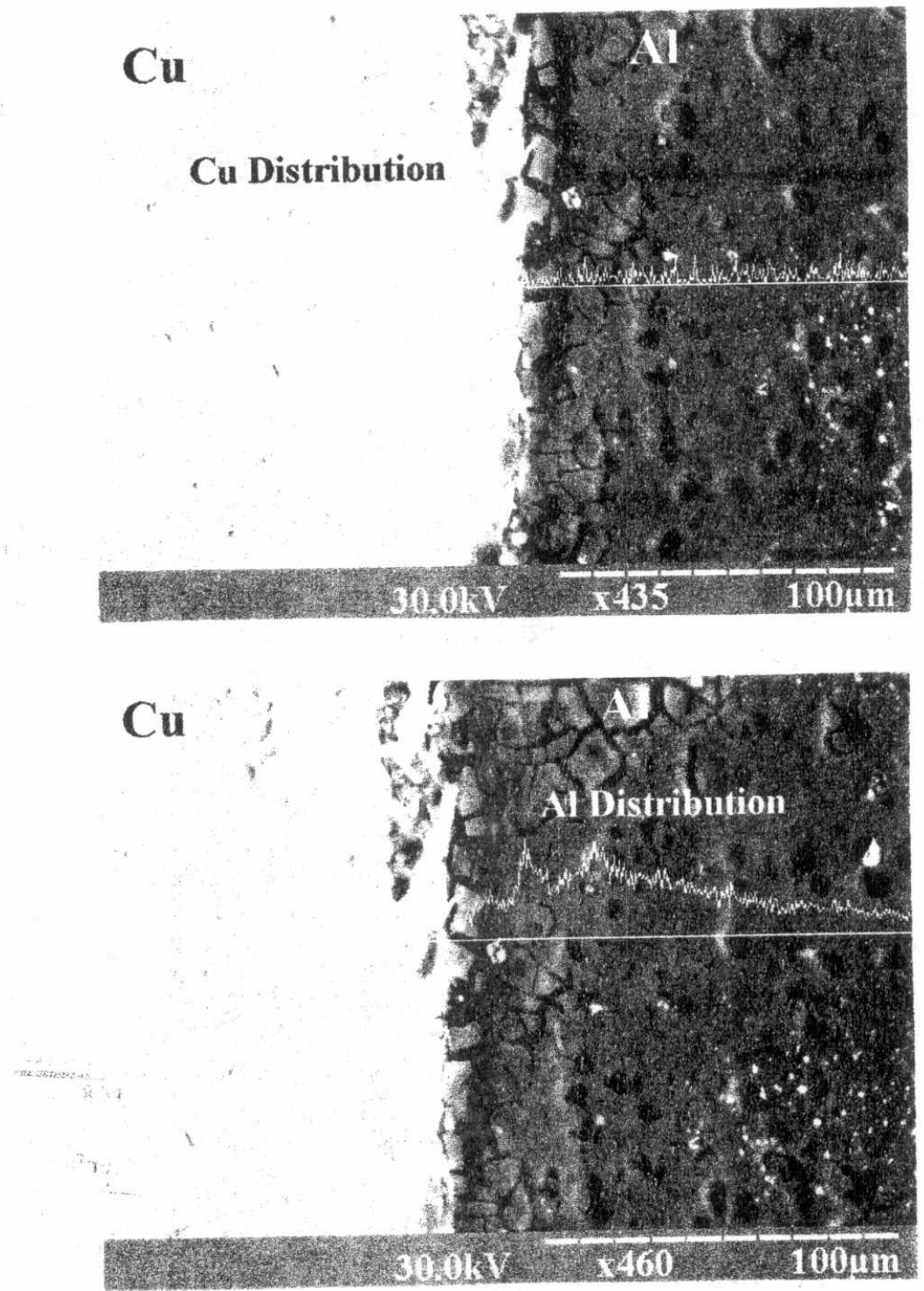

Fig. 23.Explosive welded joint of Commercially pure Aluminum and CopperNickel alloy using a stand-off distance $S=2 \mathrm{~mm}$ and an explosive ratio $\mathrm{R}=1.4$. 


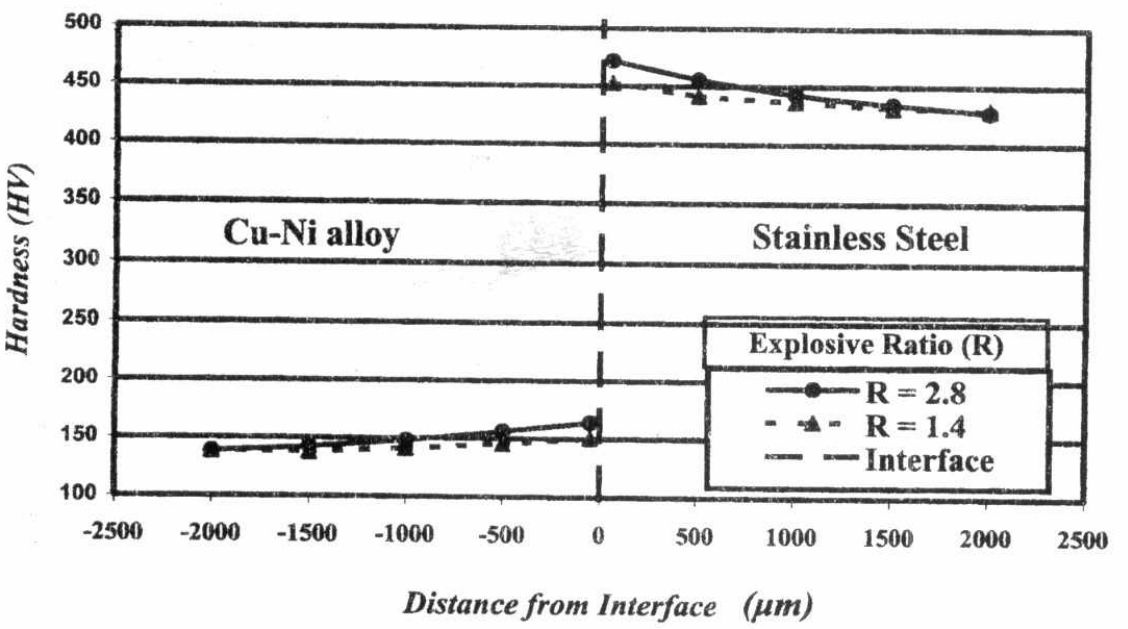

Fig. 24.Hardness distribution through the interface in the explosive welded joint of Stainless Steel and Copper-Nickel alloy obtained using a standoff distance $S=8 \mathrm{~mm}$ and an explosive ratio $\mathrm{R}=2.8$.

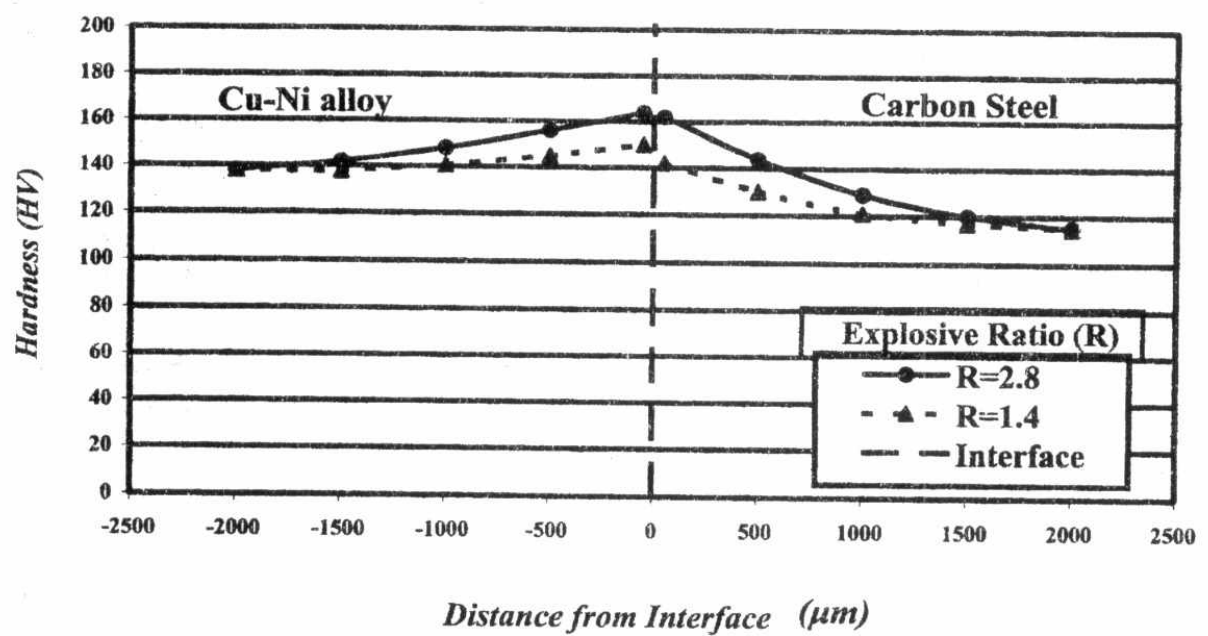

Fig. 25.Hardness distribution through the interface in the explosive welded joint of Carbon Steel and Copper-Nickel alloy obtained using a standoff distance $S=8 \mathrm{~mm}$ and an explosive ratio $R=2.8$. 


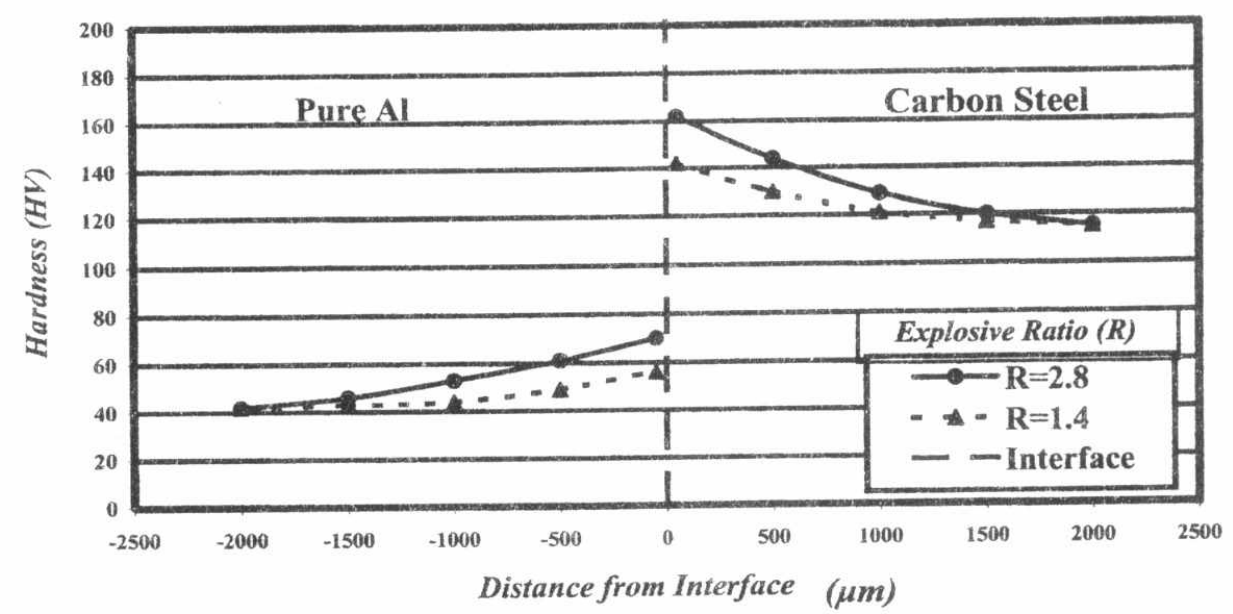

Fig. 26. Hardness distribution through the interface in the explosive welded joint of Carbon Steel and Commercially pure Aluminum obtained using a stand-off distance $S=8 \mathrm{~mm}$ and an explosive ratio $R=2.8$.

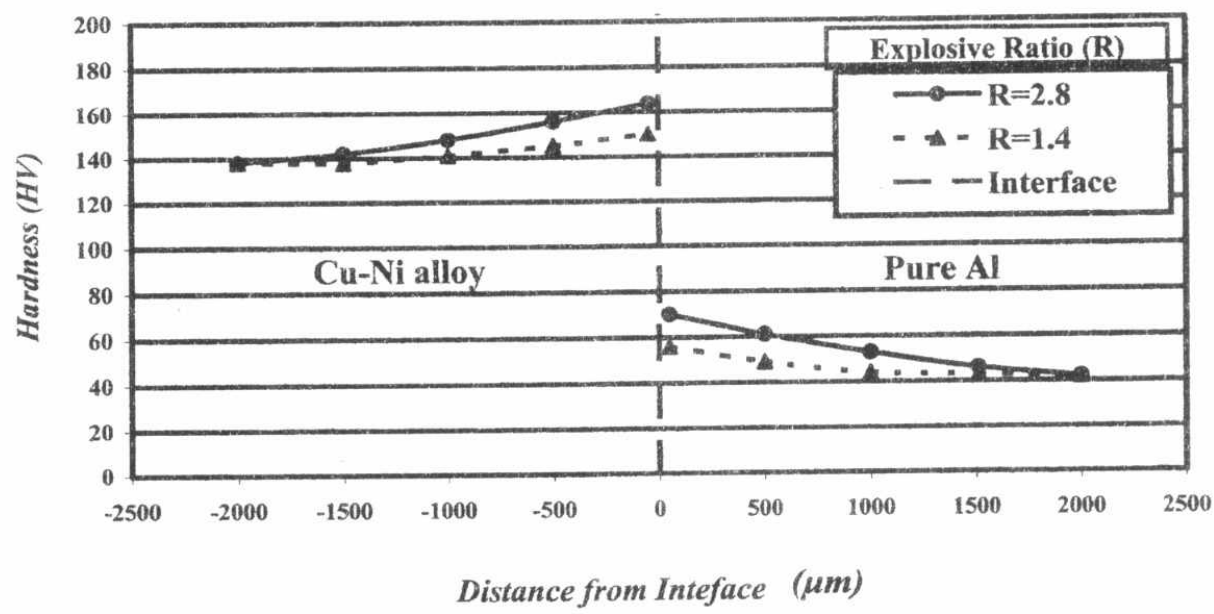

Fig. 27. Hardness distribution through the interface in the explosive welded joint of Commercially pure Aluminum and Copper-Nickel alloy obtained using a stand-off distance $S=8 \mathrm{~mm}$ and an explosive ratio $\mathrm{R}=2.8$. 